\title{
La liturgia en el Concilio Vaticano II: bases, repercusiones y desafíos de una reforma
}

\author{
Fernando Berríos \\ FACULTAD DE TEOLOGÍA \\ PONTIFICIA UNIVERSIDAD CATÓLICA DE CHILE \\ fberriosm@uc.cl
}

Resumen: "La renovación litúrgica es el fruto más visible de la obra conciliar". Tal es la constatación que hicieron los obispos del mundo al concluir el Sínodo de 1985, dedicado a la evaluación de los primeros veinte años de aplicación de las orientaciones y directrices del Concilio Vaticano II. Sin duda alguna, también en la concreta vida de la Iglesia la reforma de la liturgia, sobre todo en lo que respecta a la celebración de la Eucaristía, ha impactado de un modo especial. Pero no ha sido unánime la evaluación de dicho impacto. El presente artículo ofrece una presentación general de las bases de la reforma litúrgica, tal como ellas se expresan en la constitución Sacrosanctum Concilium y en sus principales antecedentes, así como una reflexión sobre sus repercusiones teológicas y eclesiológicas y sobre los desafíos planteados por toda una perspectiva crítica representada paradigmáticamente por Joseph Ratzinger/papa Benedicto XVI.

Palabras clave: Concilio Vaticano II, Sacrosanctum Concilium, Reforma litúrgica, Celebración eucarística.

Abstract: "The liturgical reform is the most visible fruit of Vatican II". Such a statement was uttered by bishops from all over the world, upon the conclusion of the 1985 Holy Synod, which assessed the first 20 years of application of the directives provided by the Second Vatican Council. Without the slightest doubt, this liturgical reform has also had a significant impact on the concrete life of the Church, especially when it comes to celebrating the Eucharist. But the assessment of such impact has not been unanimous. The following article provides a general view on the foundations of the liturgical reform, as expressed in Sacrosanctum concilium constitution and in its main precedents, as well as a consideration on its theological and ecclesiological consequences, and also on the challenges suggested by a critic perspective represented by Joseph Ratzinger/Pope Benedict XVI.

Keywords: Second Vatican Council, Sacrosanctum concilium, Liturgical reform, Eucharistic celebration. 
Es destacable el hecho de que la primera palabra oficial del Concilio Vaticano II se refiera a la liturgia y a su necesaria reforma: la constitución Sacrosanctum Concilium, promulgada el 4 diciembre de 1963. En ella la liturgia es presentada ante el mundo como la expresión privilegiada de una Iglesia que busca "acrecentar de día en día entre los fieles la vida cristiana, adaptar mejor a las necesidades de nuestro tiempo las instituciones que están sujetas a cambio, promover todo aquello que pueda contribuir a la unión de cuantos creen en Jesucristo y fortalecer lo que sirve para invitar a todos los hombres al seno de la Iglesia. Por eso (este sacrosanto Concilio) cree que le corresponde de un modo particular proveer a la reforma y al fomento de la Liturgia" ${ }^{1}$.

Todo ese cúmulo de objetivos, que serían objetivos centrales del Concilio en general, se plantean aquí desde una convicción de fondo: que "la liturgia, por cuyo medio 'se ejerce la obra de nuestra Redención', sobre todo en el divino sacrificio de la Eucaristía, contribuye en sumo grado a que los fieles expresen en su vida y manifiesten a los demás el misterio de Cristo y la naturaleza auténtica de la verdadera Iglesia" (SC 2). En otras palabras, la liturgia es comprendida como una especial manifestación de esta Iglesia que más tarde, en la constitución Lumen gentium, se reconocería ante todo en su dimensión de mysterium y de realitas complexa ( $L G$ I, esp. n. 8), es decir, como una realidad al mismo tiempo "humana y divina, visible y dotada de elementos invisibles, entregada a la acción y dada a la contemplación, presente en el mundo y, sin embargo, peregrina; y todo esto de suerte que en ella lo humano esté ordenado y subordinado a lo divino, lo visible a lo invisible, la acción a la contemplación y lo presente a la ciudad futura que buscamos" (SC 2).

En esta concepción eclesiológica, la liturgia tiene un rol decisivo en el despliegue del misterio de la Iglesia ad intra, para "los que están dentro para ser templo santo en el Señor y morada de Dios en el Espíritu (cf. Ef 2, 21s)", pero también ad extra, para la misión en el mundo, por cuanto ella presenta a la Iglesia "a los que están afuera, como signo levantado en medio de las naciones (cf. Is 11,12 ), para que debajo de él se congreguen en la unidad los hijos de Dios que están dispersos (Jn 11, 52), hasta que haya un solo rebaño y un solo pastor (Jn 10, 16)” (ibid.).

Constitución Sacrosanctum Concilium sobre la Sagrada Liturgia, del Concilio Vaticano II (en adelante citada como SC más el número correspondiente, en el mismo cuerpo del texto); aquí n. 1. Los destacados son míos. 
La constitución puntualiza, a partir de un fuerte fundamento bíblico, que esto es así porque la obra de la salvación realizada en Cristo, en su muerte y resurrección ( $S C$ 5), sigue aconteciendo en su Iglesia "mediante el sacrificio y los sacramentos, en torno a los cuales gira toda la vida litúrgica" (SC 6). Parafraseando el documento, podemos decir que aunque la liturgia no es la única actividad de la Iglesia ni puede sustituir la experiencia necesariamente previa de la fe y la conversión personales $(S C$ 9), en ella, y sobre todo en la liturgia eucarística, Cristo mismo posibilita a todos, de manera muy especial, la experiencia de su presencia salvífica. Por ello, con razón se la considera como "el ejercicio del sacerdocio de Cristo” en que su Cuerpo Místico, Cabeza y miembros, ejerce "una acción sagrada [...] cuya eficacia [...] no la iguala ninguna otra acción de la Iglesia” (SC 7). Esta comprensión fundamental de la liturgia en vinculación con el núcleo mismo del misterio de la Iglesia permite entender en todo su alcance el sentido y la necesidad de la reforma litúrgica planteada desde el comienzo en el Concilio Vaticano II, y que más tarde sería reconocida precisamente como "el fruto más visible" del mismo².

En las páginas que siguen quisiera esbozar una reflexión teológica sobre esta reforma, comenzando por los principios que la motivaron y guiaron (1.). En un segundo momento me referiré en líneas generales a los avatares de la reforma litúrgica en el posconcilio (2.) y luego a la crítica teológica de la misma, especialmente en lo referente a los cambios introducidos en la celebración eucarística (3.). Concluiré con algunas breves consideraciones sobre algunas cuestiones teológicas y eclesiológicas que, a mi juicio, han estado en juego en la discusión que ha acompañado la aplicación de la reforma en los últimos años.

\section{Intuiciones fundamentales del Concilio Vaticano II sobre la LITURGIA}

\subsection{Grandes principios de la reforma litúrgica: Sacrosanctum Concilium}

¿Cuál es la razón última de la reforma litúrgica propuesta por el Concilio? En otras palabras: ¿cuáles son los grandes valores que los Padres Conciliares buscaron salvaguardar mediante esta empresa tan ambiciosa

\footnotetext{
2 "La renovación litúrgica es el fruto más visible de la obra conciliar" (Relación final de la Asamblea extraordinaria del Sínodo de los Obispos, 7-XII-1985, II, B, b, 1).
} 
como audaz? Busquemos en la misma constitución Sacrosanctum Concilium la respuesta a esta pregunta, considerando el texto en su estado final ${ }^{3}$.

Ya en el capítulo I, a partir de las consideraciones recién destacadas, el documento llega a una afirmación rotunda: “...la liturgia es la cumbre (culmen) a la cual tiende la actividad de la Iglesia y al mismo tiempo la fuente (fons) de donde mana toda su fuerza" (SC 10). Este doble carácter de la liturgia como sentido último y a la vez manantial de la vida de la comunidad creyente se experimenta de un modo paradigmático en la Eucaristía. En efecto - dice la constitución- de ella "mana hacia nosotros la gracia como de su fuente y se obtiene con la máxima eficacia aquella santificación de los hombres en Cristo y aquella glorificación de Dios, a la cual las demás obras de la Iglesia tienden como a su fin" (ibid.). Por todo ello, se entiende que la constitución afirme -citando una expresión del Misal Romano- que por medio de la liturgia "se ejerce la obra de nuestra redención" (SC 2).

Ahora bien, precisamente por eso, y para que esta acción salvífica divina que acontece en la liturgia pueda experimentarse verdaderamente y en toda su eficacia, se requiere algo también activo de parte del sujeto creyente:

"que los fieles se acerquen a la sagrada liturgia con recta disposición de ánimo, pongan su alma en consonancia con su voz y colaboren con la gracia divina, para no recibirla en vano (...) los pastores de almas deben vigilar para que en la acción litúrgica no solo se observen las leyes relativas a la celebración válida y lícita, sino también para que los fieles participen en ella consciente, activa y fructuosamente (scienter, actuose et fructuose) (SC 11) ${ }^{4}$.

Tras este principio late una convicción teológica fundamental y decisiva: en la liturgia acontece la acción de Dios salvador en Cristo (cf. SC 2), pero esa acción divina no completa su efecto sino en el concurso de la acción humana creyente, que consiste en reconocer la acción divina y acogerla consciente y activamente. Al principio de la necesaria "par-

3 Cf. R. KacynsKI, "Theologischer Kommentar zur Konstitution über die heilige Liturgie Sacrosanctum Concilium”, en P. Hünermann/B. J. Hilberath (Ed.), Herders Theologischer Kommentar zum Zweiten Vatikanischen Konzil, Vol. 2 (Herder, Freiburg-Basel-Wien 2004) 1-227.

4 El destacado es mío. 
ticipación” de los fieles en la liturgia se suma así, inseparablemente, el principio de la necesaria conciencia o comprensión de lo que acontece en ella, dentro de su índole misteriosa. Porque, en definitiva, la liturgia es un acontecimiento divino-humano; en palabras de Guillermo Rosas, "no es solo obra de Dios ni, mucho menos, solo del hombre, sino de ambos simultáneamente (...) es obra de Dios y de la Iglesia y tiene a ambos por único sujeto dada la unidad del Cuerpo de Cristo que es la Iglesia presidida por Él"s. Ambos principios guías - mayor participación y mayor comprensión- son profundizados a lo largo de toda la constitución, pero sobre todo en su capítulo I ("Principios generales para la reforma y fomento de la sagrada escritura”), bosquejando así un marco que permitirá entender el sentido fundamental de la reforma ${ }^{6}$.

\subsection{Consecuencias, derivaciones}

En este primer capítulo no solo se declaran principios de la reforma litúrgica, sino que además se desarrollan fundamentaciones y profundizaciones doctrinales y se llega a ciertas concreciones importantes. Por de pronto, se puntualiza que aquella participación "plena, consciente y activa” que la constitución tan ardientemente espera de los fieles, es algo que viene exigido por "la naturaleza de la liturgia misma", es decir, que no es accesoria y que, además, a ella "tiene derecho y obligación (ius habet et officium), en virtud del bautismo, el pueblo cristiano, 'linaje escogido, sacerdocio real, nación santa, pueblo adquirido' ( 1 Pe 2, 9; cf. 2, 4-5)" (SC 14). Con esto, se adelanta ya en esta primera constitución la fuerte recuperación del sacerdocio común de los fieles que caracterizará a la eclesiología conciliar y que adquirirá un sentido literalmente fundamental en la constitución Lumen gentium. Además, es en este sentido preciso que hay que entender la afirmación previa de la liturgia como "el ejercicio del sacerdocio de Jesucristo" (SC7): en ella "el Cuerpo Místico de Jesucristo, es decir, la Cabeza y sus miembros, ejerce el culto público íntegro. En consecuencia, toda celebración litúrgica, por ser obra de

5 G. Rosas, "La fuerza positiva de la liturgia del Vaticano II. A casi 50 años de Sacrosanctum Concilium”, en Anales de Teología, 14.1 (2012) 7-26, 24. En la misma línea utiliza luego la categoría de "sinergia divino-humana" (p. 25).

6 Cf. especialmente la sección III del capítulo I: "Reforma de la sagrada liturgia” (nn. 22-38). Cf. L. Díez, "Un camino abierto al futuro. Hacia una liturgia cada vez más verdadera...”, en Sal Terrae, n. 1.177, Vol. 101/4 (2013) 327-340. 
Cristo sacerdote y de su Cuerpo, que es la Iglesia, es acción sagrada por excelencia..." (ibid.).

Los Padres Conciliares consignan además su conciencia de que esta participación sacerdotal de "todo el pueblo" no se alcanzará sin "una educación adecuada”; y esto, partiendo por el clero, para que sus miembros lleguen a ser verdaderos "maestros" de la liturgia, impregnándose primero ellos mismos "del espíritu y de la fuerza" de la misma $(S C 14)^{7}$. Esta acentuación de la importancia de la formación litúrgica confirma a su vez la convicción de que una mayor y mejor participación de todos los fieles en la liturgia solo será posible mediante una comprensión adecuada de lo que en ella acontece. Este aspecto tocaba directamente a los ritos y a los textos utilizados en ellos y a la necesidad de que unos y otros "expresen con mayor claridad las cosas santas que significan y, en lo posible, el pueblo cristiano pueda comprenderlas fácilmente y participar en ellas por medio de una celebración plena, activa y comunitaria" (SC 21 ), que no excluya tampoco el "silencio sagrado" (SC 30). En esta perspectiva es que la constitución incluye la concreta instrucción de revisar "cuanto antes" los libros litúrgicos, recurriendo a los especialistas pero al mismo tiempo "consultando a Obispos de diversas regiones del mundo" (SC 25), es decir, a las iglesias locales.

\subsection{Criterios para la aplicación de la reforma}

La constitución prevé, pues, que la reforma traerá consigo algunos cambios no menores en la liturgia, y en consecuencia los Padres Conciliares establecen ciertos criterios básicos para el efecto. Conviene recordarlos, dada la gran importancia que tendrían para la aplicación de la reforma en el posconcilio. En primer lugar, el criterio de que "la reglamentación de la sagrada Liturgia es de competencia exclusiva de la autoridad eclesiástica; esta reside en la Sede Apostólica y, en la medida que determine la ley, en el Obispo" (SC 22, 1). Es evidente que queda sin precisar la competencia del segundo. También esa reglamentación corresponde, "dentro de los límites establecidos, a las competentes asambleas territoriales de Obispos de distintas clases, legítimamente constituidas" (ibid., 2 ), con lo cual ya en esta primera constitución se abría un espacio para

Cf. también el n. 15 sobre la formación litúrgica del clero, y los nn. 17 y 18 sobre la vida litúrgica en los seminarios y casas religiosas y como parte importante de la existencia de los ministros ordenados. 
las conferencias episcopales, que el Concilio establecería de modo formal con la promulgación del decreto Christus Dominus el 28 de octubre de 1965. Pero el punto que se quería aquí subrayar, está dicho a continuación: “...nadie, aunque sea sacerdote, añada, quite o cambie cosa alguna por iniciativa propia en la liturgia” (ibid., 3). Con esto, la constitución se adelanta a una situación que de todos modos, como sabemos, se daría, pero sobre todo pone en el tapete un aspecto que sería muy sensible en la aplicación de la reforma y en la reglamentación de la vida litúrgica en general en la Iglesia posconciliar: la cuestión de si la aplicación de la reforma debía asentarse en la corresponsabilidad colegial episcopal o más bien en un modelo derechamente centralizado.

Lo recién señalado está en conexión estrecha con otro criterio: el tema de las competencias sobre la reglamentación de la liturgia y sus eventuales cambios tiene que ver ante todo con la adaptación de la misma a las circunstancias locales (SC 37-40). El texto no utiliza aquí el concepto de cultura ni el de inculturación, pero sí otras equivalentes, como "mentalidad y tradiciones", "genio y cualidades peculiares de las distintas razas y pueblos", "costumbres de los pueblos ${ }^{10} \mathrm{o}$ "tradiciones y genio" 11 . Todo ello entendido como un ámbito, en definitiva, cultural que se pretende respetar, evitando una uniformidad exagerada. Y aunque se cautela que no debe haber mezcla con "lo indisolublemente vinculado a supersticiones y errores", incluso en este caso se deja abierta la posibilidad de que se lo acepte a veces, "con tal que se pueda armonizar con el verdadero y auténtico espíritu litúrgico" (SC 37). En lo que respecta concretamente a la revisión de los libros litúrgicos, el criterio es admitir "variaciones y adaptaciones legítimas", pero salvando "la unidad sustancial del rito romano" (SC 38).

8 En el título de esta parte del documento, que corresponde a la letra d) de la sección III del capítulo I: "Normae ad aptationem ingenio et traditionibus populorum perficiendam".

9 "Ecclesia [...] variarum gentium populorumque animi ornamenta ac dotes colit et provehit;..." (SC 37).

10 “... in populorum moribus..." (loc. cit.)

11 "A competenti auctoritate ecclesiastica territoriali, de qua in art. $22 \$ 2$, sedulo et prudenter consideretur quid, hoc in negotio, ex traditionibus ingenioque singulorum populorum opportune in cultum divinum admitti possit”. Cf. también SC 81, en relación específica al rito de las exequias" (SC 40). El destacado es mío. 
Otro criterio-guía que plantea la constitución para la reforma es el de la necesidad de un "desarrollo orgánico", que asegure que los eventuales cambios o las posibles novedades se den en una clara conexión con el patrimonio litúrgico de la Iglesia. Así será posible "conservar la sana tradición y abrir, con todo, el camino a un progreso legítimo" (SC 23). Nótese que el criterio de partida es más bien conservar, por lo que será necesario cautelar que "no se introduzcan innovaciones si no lo exige una utilidad verdadera y cierta de la Iglesia, y solo después de haber tenido la precaución de que las nuevas formas se desarrollen, por decirlo así, orgánicamente a partir de las ya existentes" (SC 23) ${ }^{12}$. Como veremos, este criterio será un punto de apoyo decisivo para la crítica posconciliar de la reforma litúrgica.

Otros dos importantes criterios de la constitución para la reforma en ciernes son: la centralidad de la Sagrada Escritura en la celebración litúrgica, atestiguada por "la venerable tradición de los ritos tanto orientales como occidentales" (SC 24), y la primacía en ella de "la celebración comunitaria, con asistencia y participación activa de los fieles", de tal manera que se la prefiera siempre a "una celebración individual y casi privada" (SC 27; cf. también el n. 26). Esto, que se aplica "sobre todo" a la celebración de la Misa ${ }^{13}$ y a la administración de los sacramentos, abre una perspectiva del todo nueva y pone en cuestión la antigua costumbre de las misas privadas o celebradas normalmente en forma individual por cada ministro ordenado.

\subsection{El uso de la lengua vernácula}

Para terminar esta rápida reseña de algunas grandes líneas directrices de la constitución Sacrosanctum Concilium, es necesario hacer una referencia al tema de la incorporación de la lengua vernácula a la liturgia reformada del rito romano. Por de pronto, hay que decir que este tema no es propiamente parte de los grandes principios o de los criteriosguías de la reforma litúrgica, sino más bien una consecuencia práctica de los mismos y en especial del principio de "mayor participación" en estrecha combinación con aquel otro de "mayor comprensión". Si estos principios debían concretarse mediante la revisión de los textos y de los

\footnotetext{
12 Los destacados son míos.

13 “[...] quedando siempre a salvo la naturaleza pública y social de toda Misa” (en el mismo n. 27).
} 
ritos litúrgicos (SC 21), los Padres Conciliares tuvieron que asumir, en la misma constitución, la tarea de definir algunas "normas derivadas del carácter didáctico y pastoral de la liturgia” (SC 33-36). Y es en este contexto que se toca el tema de la lengua litúrgica.

Al cumplirse ya 50 años de la promulgación de Sacrosanctum Concilium, difícilmente los católicos de hoy -aparte de los pocos conocedores de los documentos del último Concilio- podrían imaginar que la primera afirmación que los Padres Conciliares hacen sobre este tema es que "se conservará el uso de la lengua latina en los ritos latinos, salvo derecho particular" $(S C 36,1)$; y que solo en un segundo momento y más bien como una concesión, se abre una posibilidad: "como el uso de la lengua vulgar es muy útil para el pueblo en no pocas ocasiones, tanto en la Misa como en la administración de los Sacramentos y en otras partes de la Liturgia, se le podrá dar mayor cabida..." (ibid., 2) ${ }^{14}$.

Interesante es el hecho de que en los parágrafos 3 y 4 de este célebre número 36 la constitución reconozca a la "autoridad eclesiástica territorial” competencia para determinar el uso y la extensión de la lengua vernácula, con la posibilidad de consultar con los obispos vecinos de la misma lengua $(\$ 3)$, como también para aprobar la traducción del texto latino $(\$ 4)$; aunque para las situaciones contempladas en el $\$ 3$ se precisa que "estas decisiones tienen que ser aceptadas, es decir, confirmadas por la Sede Apostólica”. La cuestión de las competencias queda, pues, en el documento mismo, en cierto sentido abierta, pues le son reconocidas en medida importante a la autoridad local; pero a la vez queda en cierto modo cerrada, por la vía de un criterio de centralización de la decisión final.

2. Reforma litúrgica y Celebración de la EuCARistía: aVATARes del POSCONCILIO

Si el Concilio reconoce, apoyándose en la tradición más antigua, a la liturgia como "la cumbre (culmen) a la cual tiende la actividad de la Iglesia y al mismo tiempo la fuente (fons) de donde mana toda su fuerza" (SC 10), entiende también, más precisamente, a la Eucaristía como "fuente y culmen (fons et culmen) de toda la vida cristiana" ( $L G 11)$. Más tarde, el Catecismo de la Iglesia Católica recalcaría además la importancia de este sacramento para la comprensión de la fe. Citando expresiones de

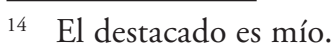


Ireneo de Lyon, la Eucaristía es allí reconocida como "el compendio y la suma de nuestra fe (, porque) 'nuestra manera de pensar armoniza con la Eucaristía, y a su vez la Eucaristía confirma nuestra manera de pensar” 15 .

Dada esta centralidad de la Eucaristía en la vida de la Iglesia y en la experiencia y comprensión de la fe de cada creyente, era comprensible que la celebración de este sacramento estuviera, como lo hemos visto, en el centro de las preocupaciones litúrgicas del Concilio Vaticano II y más específicamente en el núcleo de la sentida necesidad de la reforma. En otras palabras, si las categorías de mayor comprensión y de mayor y mejor participación estaban en el núcleo de las inquietudes que guiaron dicha reforma, ello se refería en primer lugar -aunque no exclusivamente- a la celebración de la liturgia eucarística.

\subsection{Antecedentes: la praxis eucarística preconciliar}

Últimamente ha tendido a ponerse en el tapete, por parte de los críticos, todo aquello que se habría "perdido" en esta celebración con la concreta ejecución de la reforma litúrgica en el posconcilio. Como contrapartida, conviene hacer presente la situación real de la vida eucarística en tiempos previos al Concilio. Cualquiera de nosotros puede apelar a los recuerdos de sus mayores, en especial de aquellos fieles cristianos laicos que fueron testigos directos de los cambios litúrgicos que trajo consigo el posconcilio. A través de ellos podremos reconocer los aspectos anecdóticos -y no tan anecdóticos- de una vida de fe enmarcada, antes de esos cambios, por una liturgia que estaba compuesta por ritos normalmente poco o nada comprendidos.

Y ello especialmente en la celebración eucarística, en la que a la limitación propia del uso del latín como lengua litúrgica, se agregaba el protagonismo casi absoluto del presbítero presidente en el desarrollo de la celebración, un cúmulo de gestos privativos del mismo y oraciones que él debía decir en secreto. Esto, sin mencionar el aspecto de la "orientación”, que, guste o no, implicaba para los fieles tener que "presenciar" en la misa un ritual realizado -de modo casi exclusivo- por un sacerdote que les daba la espalda. En el mejor de los casos, el de los católicos piadosos que cumplían con el precepto dominical de la misa, podía esperarse de ellos una actitud devota y, tal vez, en cierto modo, contemplativa,

15 Catecismo de la Iglesia Católica, n. 1327, citando a Ireneo, Haer., 4, 18, 5. 
pero claramente no aquella "participación plena, consciente y activa" que buscó promover con ahínco el Concilio (SC 14). ¿Cómo poder participar, es decir, cómo "tomar parte" en la liturgia si me está vedado, no en principio pero sí en la práctica, una comprensión mínima de lo que acontece en ella? Recuerdo con gran nitidez a esas señoras piadosas que en mi niñez frecuentaban la casa de mi abuela paterna, y que devotamente rezaban el rosario o respondían en la misa en latín, sin entender una sola palabra... Si así eran las cosas, es entendible que incluso hoy en día podamos ver en ciertas iglesias a personas mayores que rezan el rosario o realizan algún otro acto piadoso mientras se celebra la Eucaristía. Es la manera que tuvieron que aprender para "participar" de la misa.

Lo recién dicho se refiere a la experiencia concreta que solía darse en la liturgia eucarística preconciliar. Más preocupante aún era esa situación si se la analizaba desde un punto de vista doctrinal. Por lo mismo, pero no sin conexión con los aspectos pastorales de la problemática, en los albores del siglo pasado y acogiendo los impulsos provenientes de un ya amplio movimiento de renovación litúrgica ${ }^{16}$, el magisterio pontificio de la primera mitad del siglo XX puso este tema, y en especial el de la participación del pueblo fiel en ella, en el centro de sus preocupaciones ${ }^{17}$. Esta línea culminará en el magisterio del papa Pío XII y particularmente en la encíclica Mediator Dei ${ }^{18}$, promulgada el 20 de noviembre de 1947. Antes y sobre todo después de esta encíclica, durante este pontificado se llevaron a cabo importantes acciones tendientes a una renovación litúrgica. Especial mención merece una comisión instituida en mayo de 1948 al interior de la Sagrada Congregación de los Ritos, entre cuyos

16 Cf. B. Neunheuser, "Movimiento litúrgico”, en D. Sartore - M. Triarca (dir.), Nuevo Diccionario de Liturgia (Ed. Paulinas, Madrid 1987²) 1.365-1.382.

17 Así el papa San Pío X, en el motu proprio Tra le sollecitudine, del 22 de noviembre de 1903: "Siendo, en verdad, nuestro vivísimo deseo que el verdadero espíritu cristiano vuelva a florecer en todo y que en todos los fieles se mantenga, lo primero es proveer a la santidad y dignidad del templo, donde los fieles se juntan precisamente para adquirir ese espíritu en su primer e insustituible manantial, que es la participación activa en los sacrosantos misterios y en la pública y solemne oración de la Iglesia" (obtenido de http://www.vatican.va/holy_father/pius_x/motu_proprio/ documents/hf_p-x_motu-proprio_19031122_sollecitudini_sp.html, el 14/10/13). El destacado es mío.

18 "[... la primera encíclica dedicada exclusivamente a la liturgia" (G. PASQUaletTi, "Reforma litúrgica", en D. Sartore - M. Triarca [dir.], Nuevo Diccionario de Liturgia, 1.691-1.714, 1.692). 
principales frutos figura la reforma de la vigilia pascual (1951) y la de la Semana Santa en su conjunto (1955). Este impulso se prolongaría en el pontificado de Juan XXIII y, tras la convocación del Concilio Vaticano II, con especial intensidad en los trabajos de la comisión preparatoria para el tema de la liturgia ${ }^{19}$.

Pero volvamos atrás. No hay que olvidar que aspectos propiamente doctrinales relativos a la Eucaristía habían llegado a ponerse en tela de juicio en una cierta praxis de celebración del sacramento. En lo que atañe, por ejemplo, a la relación entre la misa y la comunión eucarística, resulta interesante el testimonio del benedictino Bernard Botte (1883-1980), director del Instituto Superior de Liturgia de París entre 1956 y 1964, en un libro de comienzos de los setenta sobre el movimiento litúrgico:

“¿Cuál era la práctica litúrgica a comienzos del siglo XX? Los jóvenes de hoy evidentemente no pueden imaginarlo. Pero los menos jóvenes [...] se atropellarían refiriéndose a sus recuerdos de infancia, porque en veinte años muchas cosas han cambiado [...] Todas las mañanas a las ocho había (en mi colegio) una misa en la capilla de los alumnos [...] La misa era dicha por un anciano sacerdote un poco demasiado áfono (aphone); incluso en la primera fila no se percibía más que un murmullo. Uno se ponía de pie para el evangelio, pero lo que era este evangelio nadie tenía el cuidado de decírnoslo. No se sabía tampoco qué santos se festejaba o por qué difuntos se celebraban misas de luto (on noir). El misal para los fieles era inexistente. Uno podía sumergirse en cualquier libro de oraciones. Pero se nos sacaba de rato en rato de nuestra somnolencia recitando en voz alta algunas decenas del rosario o cantando un motete en latín o un cántico en francés. El único momento en que se rezaba con el sacerdote era después de la misa, cuando el celebrante, arrodillado a los pies del altar, recitaba los tres Avemaría con el Salve Regina y otros rezos prescritos por León XIII. Comulgar no era asunto de esta misa. Por lo demás, en esta época nadie parecía ver una relación entre la misa y la comunión [...].

En las dos parroquias de mi ciudad natal, las cosas no eran mucho mejor. Había misas cantadas, pero eran un diálogo entre el clérigo y el organista. El pueblo permanecía mudo y pasivo [...] En cuanto a la comunión, se la podía recibir antes de la misa, después de la misa o en el medio de la misa, pero nunca en el momento previsto por la liturgia. Era una cuestión de horario: se daba la comunión todos los

19 Cf. G. Pasqualetti, "Reforma litúrgica”, en D. Sartore - M. Triarca (dir.), Nuevo Diccionario de Liturgia, 1.691-1.714, 1.692 
cuartos de hora [...] Monseñor Lalieu, doctor en teología y autor de un libro sobre la misa, consultado por una de mis hermanas acerca del mejor momento para comulgar, le aconsejó hacerlo antes de la misa y ofrecer esta en acción de gracias. Esto nos parece extraño, pero hay que tener en cuenta las ideas de la época. La misa había dejado de ser la oración de la comunidad cristiana. Era el clero el que se hacía enteramente cargo de la misa, en nombre de la comunidad. Por tanto, los fieles solo podían asociarse a ella de lejos y entregarse a su devoción personal. La comunión aparecía como una devoción privada sin un vínculo especial con la misa" ${ }^{20}$.

Sobre este trasfondo consideremos brevemente el itinerario concreto de la reforma litúrgica a partir del Concilio Vaticano II, y especialmente en el ámbito de la celebración eucarística.

2.2. Reforma de la liturgia y celebración eucarística: contextualización histórica

Pese a situaciones como las que describe el P. Botte, o tal vez precisamente como una reacción a ellas, el así llamado movimiento litúrgico fue teniendo a lo largo del siglo XX un influjo creciente en la Iglesia católica, y la asunción del tema por parte de los Papas contribuyó no poco a ello. Por eso las aproximaciones históricas al Concilio Vaticano II $^{21}$ suelen destacar la atmósfera de predominante consenso que, pese a ciertos tropiezos, desde un comienzo rodeó al tema de la liturgia e incluso a la perspectiva de su necesaria renovación. Por de pronto, no deja de impresionar el hecho de que de las 9 mil páginas de aportes y de sugerencias que llegaron a Roma desde todos los confines del mundo durante la preparación del Concilio, en torno a un $25 \%$ de ellas se referían de

20 B. Bотте, Le mouvement liturgique: témoignage et souvenirs Bernard Botte (Desclée, Paris 1973). Extractos tomados de las páginas 9, 10 y 11. Traducción mía.

21 Entre ellas destaco: R. Kacynski, "Hacia la reforma litúrgica", en G. Alberigo (dir.), Historia del Concilio Vaticano II, Vol. 3 (Ed. Sígueme, Salamanca 2006) 173-227; J. W. O’Malley, ¿Qué pasó en el Vaticano II? (Sal Terrae, Santander 2012) 175-192; G. Pasqualetti, "Reforma litúrgica", en D. Sartore - M. Triarca (dir.), Nuevo Diccionario de Liturgia. Cf. también las aproximaciones, más breves pero sugerentes, de G. Rosas, "La fuerza positiva de la liturgia del Vaticano II" (ya citado en nota 5) y C. SCHICKENDANTZ, "La promoción y reforma general de la liturgia”, en Mensaje 618 (2013) 32-33. 
algún modo a la liturgia ${ }^{22}$. Esto indicaba un acuerdo básico, a nivel de toda la Iglesia de rito romano, con los grandes principios que habían venido guiando el movimiento litúrgico y de ello pudo aprovecharse muy bien la correspondiente comisión preparatoria del Concilio. De hecho, la constitución sobre la liturgia sería el único documento que conservaría, en lo sustancial, el esquema propuesto por dicha comisión ${ }^{23}$. Finalmente, en la votación definitiva del texto, el 4 de diciembre de 1963, en el mismo día de su promulgación solemne, la Constitución sobre la Sagrada Liturgia, Sacrosanctum Concilium, obtuvo 2.147 votos a favor y solo 4 en contra.

Este exitoso resultado no puede, pues, entenderse sino en vinculación con la calidad del trabajo de la comisión preparatoria y con la atmósfera general de aprobación de las grandes líneas que lo guiaron. La comisión, que constaba con 65 miembros y asesores, estaba presidida por el cardenal Gaetano Cicognani, entonces prefecto de la Congregación de Ritos, y su secretario era el P. Annibale Bugnini, experto liturgista que había asesorado al papa Pío XII y que ejercía entonces como profesor en las universidades Lateranense y Urbaniana de Roma. Se lo considera el hombre clave tras la reforma litúrgica, partiendo por su eficiente coordinación de los trabajos de esta comisión, que ya en enero de 1962 produjo un documento coherente para ser presentado al próximo Concilio.

El cardenal Cicognani falleció el 5 de febrero de 1962 y el 22 de ese mismo mes el papa Juan XXIII nombró al cardenal español Arcadio María Larraona como nuevo prefecto de la Congregación de Ritos y presidente de la comisión preparatoria sobre la liturgia. Al parecer debido al alineamiento del cardenal Larraona con los sectores eclesiásticos más conservadores en estos meses previos al Concilio, los impulsos antes dados sobre el tema litúrgico sufrieron algún freno importante ${ }^{24}$. Llegado el momento, el cardenal Larraona sería nombrado, como se esperaba, presidente de la Comisión Litúrgica en el Concilio mismo, aunque tuvo que lidiar con un documento que no lo representaba. En la primera reunión de la Comisión, el 21 de octubre de 1962, sacó a Bugnini de

22 Dato del especialista austríaco en liturgia Josef Andreas Jungmann, S.J., perito en el Concilio; citado por K. Rahner - H. Vorgrimler, Kleines Konzilskompendium (Herder, Freiburg-Basel-Wien $\left.{ }^{28} 2000\right) 37$.

23 Cf. G. Pasquale, "Reforma litúrgica", 1.692.

24 Cf. J. W. O’Malley, ¿Qué pasó en el Vaticano II?, 178. 
la secretaría, por considerarlo excesivamente progresista y, peor, el gran responsable del esquema heredado sobre la liturgia. Bugnini sería así el único secretario de una comisión preparatoria que no continuaría en su cargo en la respectiva comisión conciliar. Fue reemplazado por Ferdinando Antonelli, un sacerdote franciscano que trabajaba en la curia, pero que no había tenido ninguna participación en la preparación del documento. El P. Bugnini fue además apartado de su cátedra de liturgia en la Universidad Lateranense y sufrió presiones en este mismo sentido, aunque sin éxito, en la Universidad Urbaniana ${ }^{25}$. Pese a este importante tropiezo, el proceso del documento sobre la liturgia siguió su curso original y Antonelli - "tal vez para consternación de quienes lo habían promovido", como ha acotado John O’Malley- al parecer no hizo nada contra el legado de Bugnini, sino que más bien se mostró como "un intérprete y transmisor imparcial" del mismo ${ }^{26}$.

Una vez aprobada la constitución Sacrosanctum Concilium, con el motu proprio Sacram Liturgiam del 26 de enero de 1964 se inició todo un programa para poner en práctica sus orientaciones. Entre las medidas, la más importante, por su carácter fundamental, sería la institución de un organismo encargado de guiar la renovación litúrgica: el Consilium ad exsequendam constitutionem de sacra liturgia. Al parecer, Pablo VI vio claro que no sería posible ejecutar la reforma recurriendo a la orgánica de la curia, pues ello le habría significado una reestructuración de funciones tan ardua, que habría demorado las cosas más de lo tolerable. Por ello, finalmente optó por este Consilium compuesto por representantes de la Iglesia universal y con el encargo de responder personalmente ante él ${ }^{27}$. Se nombró como presidente al cardenal Giacomo Lercaro, entonces arzobispo de Bolonia. El cardenal Larraona, que en ese momento todavía era prefecto de la Congregación de Ritos, sería parte del Consilium, pero sin presidirlo ${ }^{28}$. Y para mayor sorpresa de algunos, el papa Pablo VI nombró como secretario de este nuevo consejo al P. Annibale Bugnini. En enero de 1968 asumiría la presidencia el cardenal Benno Gut.

25 Cf. A. Bugnini, La Riforma Liturgica (1948-1975) (CLV-Ed. Liturgiche, Roma 1983) 26-49. Para los aspectos aquí aludidos, cf. especialmente 41, nota 4.

26 J. W. O’Malley, ¿Qué pasó en el Vaticano II?, 179.

27 Cf. R. KACYNSKI, "Hacia la reforma litúrgica", 221.

28 J. W. O’Malley, ¿Qué pasó en el Vaticano II?, 190. 
El Consilium era un organismo con un doble nivel de funcionamiento: un núcleo central de consultores y un amplio círculo de consejeros, distribuidos en unos cuarenta grupos de estudios. Los consultores tenían por tarea sancionar los esquemas o propuestas que debían ser sometidos a la consideración del Papa; los grupos de consejeros debían estudiar diversos problemas y proponer proyectos de reforma. Un tema importante, el del estatuto administrativo y de las competencias del Consilium, se fue delineando en el proceso mismo de la ejecución de su tarea. Basándose en documentación de los años 1964 a 1966, Gottardo Pasqualetti, quien fuera colaborador de este consejo, lo describe como "un organismo colateral a la Sagrada Congregación de los Ritos, que conservaba la responsabilidad jurídica en lo que se refería a la liturgia”; y luego como "un órgano cualificado de estudio con funciones administrativas al mismo tiempo, bajo la directa dependencia del Papa" ${ }^{29}$. Esta dependencia, pero sobre todo el apoyo y el interés personal del papa $\mathrm{Pa}$ blo VI en el tema de la liturgia, fueron factores que permitieron superar momentos de crisis y, sobre todo, que dieron confianza a los obispos y a los expertos liturgistas de todo el mundo en relación al proceso guiado por el Consilium ${ }^{30}$. Como veremos, no faltaron excepciones a este clima generalizado de consenso. Al año 1970 ese programa de trabajo podría mostrar como resultado nada menos que 13 asambleas plenarias, y en torno a ellas innumerables reuniones de trabajo, 365 esquemas para ser discutidos en dichas asambleas, la revista especializada Notitiae a partir de 1965 y múltiples documentos y propuestas de renovación litúrgica ${ }^{31}$.

Un último hecho importante en esta breve pero intensa historia es la decisión de Pablo VI de crear, el 8 de mayo de 1969, la Sagrada Congregación para el Culto Divino como órgano permanente de atención y promoción de la vida litúrgica, absorbiendo en su estructura al Consilium. Su primer prefecto fue el cardenal Gut y su secretario, el P. Annibale Bugnini, a quien Pablo VI conferiría la ordenación episcopal el 13 de febrero de 1972. Finalmente, en 1975 se realizó una fusión con otra entidad de la curia, convirtiendo así el dicasterio litúrgico en la nueva Sagrada Congregación para los Sacramentos y el Culto Divino.

\footnotetext{
29 G. PASQUAletti, "Reforma litúrgica”, 1.693.

30 G. Pasqualetti, "Reforma litúrgica", 1.693.

31 Cf. el informe del cardenal Gut al papa Pablo VI en la audiencia del 10 de abril de 1970, publicado en Notitiae 6 (1970) 224-225.
} 


\subsection{Los frutos de la reforma}

¿Qué frutos concretos trajo todo este proceso de ejecución de la reforma litúrgica alentada por el Concilio? Describámoslo brevemente, sobre todo, como dijimos, en lo que se refiere a la liturgia eucarística. Por de pronto, la introducción del uso de la lengua vernácula, pero ciertamente trascendiendo la perspectiva más bien cauta que se encuentra en el texto mismo de la constitución Sacrosanctum Concilium (especialmente en los números 36 y 54). Dado que la constitución había dejado un espacio a la autoridad de la iglesia local en cuanto a "determinar si ha de usarse la lengua vernácula y en qué extensión” (SC 36, 3), en la práctica ello derivó en una amplia generalización de tal uso, sobre todo en la celebración de la misa. Como bien ha observado Carlos Schickendantz, en esto puede verse "en funcionamiento la perspectiva pastoral del Concilio: beneficiar la participación activa"32.

Pero la reforma no apuntaba simplemente a una traducción lingüística, sino a otra de índole más profunda, que permitiera verdaderamente a todos los fieles aproximarse a la obra de la redención que acontece, misteriosamente, en la liturgia (cfr. SC 2) y participar en ello con fe y compromiso personales, a la vez que con profundo sentido comunitario. En esa perspectiva, el Consilium introdujo en una primera etapa, a partir de la instrucción Inter oecumenici del 26 de septiembre de $1964^{33}$, ciertas modificaciones que era posible hacer con los libros litúrgicos aún no revisados. Por ejemplo, la adaptación de las iglesias, con el altar versus populum y el ambón como lugar expresivo de la centralidad de la proclamación de la Palabra en la celebración eucarística; la introducción de la "oración común" o de los fieles (cf. SC 53), la obligación de la homilía dominical (cf. SC 52), la simplificación de los ritos para una mejor comprensión de cada una de las partes de la misa y a la vez de su unidad (cf. SC 50 y 56), etc. Pero sobre todo, la fuerte recomendación

\footnotetext{
C. SCHICKENDANTZ, "La promoción y reforma", 32.

33 A esta instrucción siguieron otras dos: Tres abhinc annos, del 4 de mayo de 1967; y Liturgicae Instaurationes, del 5 de septiembre de 1970. Cf. su presentación comentada en A. Bugnini, La Reforma Liturgica, 796-817. Para el tema de la Eucaristía es especialmente importante la instrucción Eucharisticum mysterium, del 25 de mayo de 1967, con una visión doctrinal más unitaria del misterio eucarístico como cena del Señor, memorial de su muerte y resurrección, presencia real, sacramento constituyente y signo privilegiado de la unidad de la Iglesia y, con todo ello, "fuente y culmen de toda la vida cristiana" (cf. $L G 11$ ).
} 
de la comunión eucarística de los fieles e incluso el reconocimiento de la posibilidad de la comunión bajo las dos especies en ciertas ocasiones, revirtiendo así una costumbre medieval que se había profundizado en el catolicismo postrindentino como una forma de contrastar la práctica protestante de compartir el cáliz (cf. SC 55). Por último, la concelebración, en cuanto expresión de la eucaristía como memorial del único sacerdocio de Cristo y vínculo de unidad por excelencia del pueblo de Dios en torno al mismo altar y misma mesa de la Cena del Señor (cf. $S C 57)^{34}$.

Una segunda fase de la reforma decantó con la publicación de los libros litúrgicos revisados y renovados (misal, liturgia de las horas, leccionarios, rituales de los sacramentos, etc.). De especial interés para nuestro tema es la publicación del nuevo Ordo Missae en 1969 (segunda edición en 1981) y del Missale Romanum completo en 1970 (segunda edición en 1975$)^{35}$.

Con este conjunto de acciones se buscó llevar a la práctica los grandes principios de la renovación litúrgica formulados en la constitución Sacrosanctum Concilium.

\section{Crítica teológica de la reforma: la voz de J. Ratzinger/Benedicto XVI}

Un aspecto muy importante -y muy polémico- del posconcilio ha sido precisamente el de la recepción de la reforma litúrgica o, según la precisión de los más críticos, de la manera concreta en que han sido ejecutados los impulsos conciliares sobre este tema central para la Iglesia.

Se suelen distinguir cuatro posturas principales ${ }^{36}: 1$ ) la de los satisfechos, en general o completamente, con la reforma; 2) la de los que

34 Cf. M. Augé, "Concelebración eucarística”, en D. Sartore - M. Triarca (dir.), Nuevo Diccionario de Liturgia, 410-423, esp. 414-423.

35 Entre 1968 y 1975 se publicaron los Ordo para las celebraciones de los demás sacramentos y la liturgia de las Horas. Cf. G. PASQualetTI, "Reforma Litúrgica”, 1.698-1.700; P. Farnés - I. Scicolone, "Libros litúrgicos", en D. Sartore - M. Triarca (dir.), Nuevo Diccionario de Liturgia, 1.127-1.144, esp. 1.135-1.142 (acápite VII. Los libros del Vat. II).

36 Cf. por ejemplo C. SChickendantz, "La promoción y reforma", 32s y las distinciones de Gilles Routhier citadas por M. Augé, "Le linee di interpretazione dell'attuale riforma litúrgica”, Lateranum, N 1, Vol. 79 (2013) 149-162, 160. 
nunca aceptaron estos cambios, así como ningún otro de los propuestos por el Concilio, por considerarlos una "traición a la Tradición", y que en su versión más extrema se dio desde un comienzo en los lefebvristas; 3) la de los que, en la orilla opuesta, han considerado insuficiente la aplicación de la reforma y que esperarían que ella fuera algo permanente y estuviera "guiada más por el principio de inculturación que por el de traducción" ${ }^{37}$; y 4) por último, la de aquellos que se consideran en comunión con la enseñanza de la constitución Sacrosanctum Concilium, pero no comparten el modo cómo ella ha sido aplicada, de un modo especial en la revisión y reforma de los textos litúrgicos. En este grupo habría que considerar al cardenal Joseph Ratzinger, como figura destacada de toda una corriente de "crítica teológica" 38 a la aplicación de la reforma ${ }^{39}$; crítica que más tarde, como papa Benedicto XVI, no tendría inconvenientes en mantener e incluso expresar en medidas importantes desde su autoridad pontificia.

\subsection{Lo que está en juego (según la crítica)}

El núcleo de esta crítica teológica se refiere a lo que Ratzinger considera la mayor contradicción al espíritu de la renovación litúrgica alentada por la constitución Sacrosanctum Concilium, esto es, que no se ha aplicado en su ejecución el principio fundamental de que "las nuevas formas se desarrollen [...] orgánicamente a partir de las ya existentes" (SC 23). Lo que ha habido más bien en el posconcilio, en su visión, es una ruptura con la historia de la Iglesia y su más auténtica tradición litúrgica. Se ha ignorado, en definitiva, que la liturgia es, de por sí, "algo orgánico, que crece, y cuyas leyes de crecimiento determinan las posibilidades de de-

37 C. SChickendantz, "La promoción y reforma", 33. El autor menciona y reseña aquí brevemente cada una de estas posturas.

38 Expresión de J. F. Baldovin, Reforma litúrgica: una réplica a sus críticos (Buena Prensa, México 2010) esp. 67-109 (“Base histórica de la Reforma”) y 111-147 ("Una crítica teológica").

39 Cf. las siguientes obras de J. RATZINGER, La fiesta de la fe: ensayo de teología litúrgica (Desclée de Brouwer, Bilbao ${ }^{3} 1999$. Original: Das Fest des Glaubens. Versuche zur Theologie des Gottesdientes [Johannes, Einsiedeln 1981]); Un canto nuevo para el Señor: la fe en Jesucristo y la liturgia hoy (Ed. Sígueme, Salamanca 1999. Original: Ein neues Lied für den Herrn. Christusglaube und Liturgie in der Gegenwart [Herder, Freiburg i.B. 1995]); El Espiritu de la liturgia. Una introducción (Ed. Cristiandad, Madrid 52009. Original: Der Geist der Liturgie. Eine Einführung [Herder, Freiburg i.B. 2000]). 
sarrollo posterior” ${ }^{40}$. Más aún, después del Concilio Vaticano II (léase: a través de la ejecución concreta de la reforma), "la idea de la liturgia como algo que nos precede, y que no puede ser 'elaborado' según el propio criterio, se perdió en la conciencia más difundida en Occidente” ${ }^{\text {"41. }}$.

En cambio, se habría desarrollado una comprensión nefasta de la libertad y de la creatividad en la liturgia. Tomando como referencia la experiencia de la libertad y de la creatividad en el arte, reflexiona:

“[...] la libertad así concebida está vacía: no libera [...] Este tipo de creatividad no puede tener cabida en la liturgia [...] La liturgia es la entrada de Dios (der Ein-Fall Gottes) en nuestro mundo [...] y obrando verdadera liberación. Solo Él puede abrir la puerta hacia la libertad. Cuanto más se entreguen los sacerdotes y los fieles con humildad a este hacerse el encontradizo de Dios ${ }^{42}$, tanto 'más nueva' será la liturgia y tanto más personal y verdadera llegará a ser. Pero la liturgia no llega ser personal, verdadera y nueva con invenciones banales de palabras (banale Worterfindungen) o jugueteos (Spielerein), sino con la audacia de ponerse en el camino hacia esa grandeza que por medio del rito siempre nos lleva la delantera y que nunca alcanzamos del todo" ${ }^{\prime 3}$.

La liturgia nos invita así, en la visión del cardenal teólogo, a una experiencia de libertad que se concreta más bien en la entrega total y confiada de sí mismo a Otro. En sí misma la liturgia es "un entrenamiento para acoger al totalmente Otro, a Dios, y dejarse moldear y utilizar por Él"44. Y ello pasa necesariamente por la acogida confiada y reverente de lo que la Iglesia nos ha transmitido para nuestra "verdadera liberación".

En el fondo, esta crisis experimentada en la concepción y en la vivencia de la liturgia es expresión de otra más profunda y radical: la de la idea de Iglesia, de la eclesiología, a la que también se refirió de modo agudo en el célebre Informe sobre la fe $e^{45}$. Una Iglesia en que, de tanto subrayar unilateralmente la imagen de "pueblo de Dios", perviven "sugestiones políticas, partidistas y colectivistas" que no dejan ver su sentido "como Iglesia del Señor, como espacio de la presencia real de Dios en el

\footnotetext{
40 J. Ratzinger, El espiritu de la liturgia, 207.

41 J. Ratzinger, El espiritu de la liturgia, 208.

42 Una mejor traducción de esta expresión podría ser: "este irrumpir de Dios".

43 J. Ratzinger, El espiritu de la liturgia, 211.

44 J. Ratzinger, El espiritu de la liturgia, 219.

45 J. Ratzinger - V. Messori, Informe sobre la fe (B.A.C., Madrid 1985) esp. 53-62.
} 
mundo" 46 . Por ello -concluye el cardenal en otro lugar de esta entrevista-, en definitiva "se ha dispersado el propium litúrgico, que no proviene de lo que nosotros hacemos, sino del hecho de que aquí acontece Algo que todos nosotros juntos somos incapaces de hacer [...] lo absolutamente Otro que, a través de la comunidad (la cual no es dueña, sino sierva, mero instrumento), llega hasta nosotros" ${ }^{\prime 7}$.

Con razón se ha observado ${ }^{48}$ que las críticas del entonces cardenal Ratzinger no se referían tan solo a los "excesos litúrgicos" cometidos después del Concilio en un clima de experimentación por momentos errático, sino a la política oficial misma que guió la puesta en ejecución de la reforma, sobre todo con la aplicación de los libros litúrgicos renovados. Punto delicado, si tomamos en cuenta un aspecto que ya hemos destacado: que este proceso, incluida la renovación del ritual de la misa mediante la constitución apostólica Missale romanum de 1969, fue llevado a cabo con el compromiso y la responsabilidad personales del papa Pablo VI.

Por todo lo anterior, no resulta extraño que ya como Papa Benedicto XVI, el cristiano y teólogo preocupado por los derroteros de la Iglesia en el posconcilio haya asumido el desafío de introducir en el ámbito de la liturgia algunos correctivos tendientes a la superación de la por él constatada "ruptura" con la tradición acaecida con la puesta en ejecución de la reforma. Un hito especialmente importante ha sido la carta apostólica en forma de motu proprio, Summorum Pontificum, del 7 de julio de 2007, sobre el uso de la liturgia romana anterior a la reforma efectuada en 1970. Profundizando un documento del papa Juan Pablo II de $1988^{49}$, establece para la celebración de la misa "dos usos del único rito romano": uno ordinario, correspondiente al misal de Pablo VI de 1969; y otro extraordinario, correspondiente al misal Romano de san Pío V en su última versión anterior al Concilio, autorizada por Juan XXIII. En la carta a los obispos que acompaña al documento, Benedicto XVI reitera una afirmación importante del mismo: "que la edición típica del Misal

46 J. Ratzinger - V. Messori, Informe sobre la fe, 55 s.

47 J. Ratzinger - V. Messori, 139. Los subrayados son parte del texto citado.

48 Cf. C. Schickendantz, "La reforma litúrgica: Un diagnóstico con poco consenso del obispo emérito de Roma”, en Mensaje 617 (2013) 40- 43, 41.

49 Papa Juan Pablo II, carta apostólica Eccleia Dei en forma motu proprio, 2 de julio de 1988. Disponible en: http://www.vatican.va/holy_father/john_paul_ii/ motu_proprio/documents/hf_jp-ii_motu-proprio_02071988_ecclesia-dei_sp.html, obtenida el 20/10/2013. 
Romano promulgado por el beato Juan XXIII en 1962 [...] nunca se ha abrogado como forma extraordinaria de la Liturgia de la Iglesia” (art. 1). De ese modo el Papa germano se adelantaba a la previsible inquietud de que con esta medida "se menoscabe la autoridad del Concilio Vaticano II y de que una de sus decisiones esenciales - la reforma litúrgica- se ponga en duda”. Más bien justifica, en la misma misiva, a aquellos fieles (aparte de los seguidores del arzobispo Lefebvre) que se han manifestado todavía ligados al rito romano preconciliar:

"Muchas personas que aceptaban claramente el carácter vinculante del Concilio Vaticano II y que eran fieles al Papa y a los Obispos, deseaban no obstante reencontrar la forma, querida para ellos, de la sagrada Liturgia. Esto sucedió sobre todo porque en muchos lugares no se celebraba de una manera fiel a las prescripciones del nuevo Misal, sino que este llegó a entenderse como una autorización e incluso como una obligación a la creatividad, lo cual llevó a menudo a deformaciones de la Liturgia al límite de lo soportable" ${ }^{50}$.

Todas estas perspectivas y principios confluyen de manera especial en la visión del actual Papa emérito sobre la correcta celebración de la Eucaristía. Su postura de base es no introducir nuevos cambios de fondo en la liturgia (pues estima que ya los ha habido de sobra), pero sí hacer una amplia evaluación teológica crítica de los cambios introducidos con la reforma litúrgica, sobre todo en la forma de celebración de la misa, recuperar el sentido teológico profundo de algunos ritos preconciliares, y finalmente proponer algunos cambios menores - pero no insignificantes- para reforzar la visión teológica que él ha querido resaltar en la celebración litúrgica en general y sobre todo en la de la Eucaristía.

A la base de este planteamiento general, a menudo subraya la distinción entre su fidelidad y adhesión a los grandes principios de la constitución Sacrosantum Concilium y su visión crítica de la concreta ejecución posconciliar de la reforma litúrgica. El ejemplo tal vez más elocuente, para él, es el tema de la introducción del uso de la lengua vernácula. Ya hemos constatado el "salto" que históricamente se dio en el mundo entero desde la propuesta más bien conservadora de la constitución en este punto, a su aplicación. Para J. Ratzinger, esto manifiesta, lisa y

50 La carta está disponible en: http://www.vatican.va/holy_father/benedict_xvi/ letters/2007/documents/hf_ben-xvi_let_20070707_lettera-vescovi_sp.html, obtenida el 20/10/2013. 
llanamente, "el contraste entre los textos del Vaticano II y las sucesivas aplicaciones concretas". Para él, "la lengua litúrgica no era de modo alguno un aspecto secundario [...] Es probable que la desaparición de una lengua litúrgica común venga a reforzar las tendencias centrífugas entre las diferentes áreas católicas" ${ }^{1}$. De hecho, una de sus acciones más impactantes en el uso de su autoridad pontificia en materia litúrgica ha sido el restablecimiento de la traducción literal de las palabras del Señor sobre el cáliz en el momento de la consagración (“...esta es mi sangre de la alianza, que es derramada por muchos", y ya no "por todos": Mc 14, 24; cf. Mt 26, 28), pese a la oposición de importantes conferencias episcopales, como la de Alemania. Precisamente, en una carta enviada por Benedicto XVI al presidente de dicha conferencia, se hace la distinción clara entre traducción e interpretación en lo que se refiere a la Sagrada Escritura, y de allí deduce el criterio: "La Palabra debe estar presente tal y como es, en su forma propia, tal vez extraña para nosotros; la interpretación debe confrontarse con la fidelidad a la Palabra misma, pero, al mismo tiempo, ha de hacerla accesible al oyente de hoy". En todo caso, concluye, "en la nueva traducción del Misal, la expresión 'pro multis' debe ser traducida tal y como es, y no al mismo tiempo ya interpretada. En lugar de la versión interpretada 'por todos', ha de ponerse la simple traducción 'por muchos"” 52 .

\section{2. "Orientación” y "forma" de la liturgia eucarística}

En cuanto a la índole esencial de la celebración de la Eucaristía, su principal observación teológica apunta a que la comunidad creyente debe percibir que lo importante y lo central no es lo que ella pueda "hacer", ya que la liturgia es ante todo una obra de Dios entre nosotros, una acción suya que nos precede y que es para nosotros pura gracia. Si en la celebración eucarística la comunidad eclesial se reúne, esto no tiene su sentido en el puro encuentro interpersonal, sino en la referencia de cada uno de los creyentes y de la comunidad en su conjunto a Dios Padre, en Cristo, con el Espíritu Santo. La liturgia y sobre todo la celebración eucarística es un volverse a Dios, para alabarlo y glorificarlo por su acción

51 J. RatZinger - V. Messori, Informe sobre la fe, 135.

52 Carta del papa Benedicto XVI al presidente de la conferencia episcopal alemana, con fecha 14 de abril de 2012 (disponible en: http://www.vatican.va/holy_father/ benedict_xvi/letters/2012/documents/hf_ben-xvi_let_20120414_zollitsch_ sp.html), obtenida el 21/10/2013. 
salvífica que aquí se presencializa como don para nosotros. Esto tiene consecuencias tanto para la comprensión de la Eucaristía en su sentido más fundamental y profundo, como para el significado de las formas litúrgicas que en ella la comunidad realiza (o debería realizar). Como se ha dicho, no estuvo en la intención del papa Benedicto XVI impulsar un abandono de la celebración versus populum para retomar la antigua forma de celebración orientada hacia el este. Pero sí se preocupó, en sus escritos, de resaltar el profundo sentido teológico de dicha práctica, así como los peligros de la nueva, que son básicamente los peligros de una comunidad eclesial que ya no está vuelta hacia Cristo, el Sol naciente, sino que tiende a cerrarse en sí misma. En la misa, según esto, no tiene sentido que siempre los cristianos nos miremos mutuamente; lo que como Iglesia deberíamos hacer siempre, y sobre todo en la Eucaristía, es mirar a Cristo y, en Él y con Él, al Padre, autor de nuestra salvación. Ya que no se intentaría restaurar la antigua "orientación" de la celebración eucarística, el papa Benedicto propuso otras medidas litúrgicas en el mismo sentido y sobre todo, destacar la centralidad de la cruz, puesta para ese efecto en medio del altar y por tanto en el centro de las miradas del presidente y del resto de la asamblea, para que todos juntos puedan volverse hacia la imagen del Crucificado, fuente única de la salvación y de la reconciliación con $\operatorname{Dios}^{53}$.

La misma perspectiva de fondo se encuentra en las observaciones de J. Ratzinger acerca de la "forma y contenido de la celebración eucarística" ${ }^{54}$. ¿Cuál es, más allá de las rúbricas y de los ritos particulares, la "forma (Gestalt) común orientadora" de la misa, aquello que la constituye y la expresa en su sentido más propio? Nuestro autor parte constatando la respuesta que a esta pregunta dieron a mediados del siglo XX teólogos importantes del movimiento litúrgico alemán, como Joseph Pascher y Romano Guardini: la forma de la eucaristía está indicada en su versión original, en los gestos de Jesús en la Última Cena. "De ella parece resultar con una claridad irrefutable que la forma esencial de la Eucaristía es una comida" ${ }^{55}$. Pero luego, todo el resto de su ensayo es una deconstrucción laboriosa y minuciosa de esta primera respuesta, a la que problematiza dogmáticamente desde el inicio por su sabor luterano

53 Cf. las "observaciones sobre el problema de la orientación de la celebración”, en J. RatZinger, La fiesta de la fe..., 185-194.

54 J. Ratzinger, La fiesta de la fe..., 43-66.

55 J. Ratzinger, La fiesta de la fe..., 45. 
y su consecuente contradicción de la doctrina eucarística del Concilio de Trento con su acento en el sacrificio. A partir de ese problema se habría planteado, precisamente, en esos autores una separación tajante $-\mathrm{y}$, ciertamente, para él nefasta- entre la forma litúrgica (una comida) y la esencia dogmática (un sacrificio) del sacramento central del cristianismo. Para Ratzinger, la falta de claridad sobre la relación entre estas dos esferas -litúrgica y dogmática- también "constituye el problema central de la reforma litúrgica" ${ }^{6}$, por lo que se propone despejarla "a través de un análisis crítico del contenido de la tesis principal que interpreta la Eucaristía como una comida" ${ }^{57}$. No podemos describir aquí en detalle cada paso de esta deconstrucción crítica, de modo que tendremos que conformarnos con destacar algunas de sus afirmaciones fundamentales y conclusiones principales.

Por de pronto, citando estudios de fuentes de J. A. Jungmann, destaca que en las primeras formas litúrgicas "la Eucharistia (la oración del memorial con forma de acción de gracias) alcanza su supremacía sobre la comida en cuanto tal." Y por lo tanto, "la forma básica no es [...], por lo menos a partir de los primeros siglos, la comida en sí, sino la Eucharistia"58. En esta distinción, para Ratzinger, no quedan totalmente separados el ámbito litúrgico (la forma) y el dogmático (el contenido teológico), sino que convergen: “...Eucharistia también es (pero no solo) bendición de la Sagrada Cena; pero el simbolismo de la cena está subordinado e integrado en otro mayor" 59 . Luego Ratzinger hace todo un análisis de la evolución histórica de la forma de la Eucaristía en los comienzos de la Iglesia. Citando a Schürmann, distingue tres grandes fases: la primera es lo que él llama "la Eucaristía de la Última Cena de Jesús”. Destaca aquí que los gestos eucarísticos de Jesús son gestos comensales, pero con autonomía y con un sentido propio, distintivo de la comida en sí; además, es algo nuevo, "aunque inmerso en un marco antiguo", lo cual permite entender que en el relato se lo ofrece para su repetición y disociándose del contexto original en que probablemente se celebró, el de la pascua judía ${ }^{60}$. Ahora bien, no hay que olvidar que "si bien la Última Cena de Jesús es el principio de toda la liturgia cristiana,

\footnotetext{
56 J. Ratzinger, La fiesta de la fe..., 47.

7 J. Ratzinger, La fiesta de la fe..., 47.

58 J. Ratzinger, La fiesta de la fe..., 48.

59 J. Ratzinger, La fiesta de la fe..., 50. El destacado está en el texto citado.

60 J. Ratzinger, La fiesta de la fe..., 53.
} 
ella misma no es todavía liturgia cristiana", y por lo tanto, "la Última Cena es la base del contenido dogmático de la Eucaristía cristiana, pero no su forma litúrgica" ${ }^{61}$. Ratzinger se apresura en explicar que esto no es "decadencia"; por el contrario: "la unidad con Jesús se tiene que buscar [...] necesariamente en la discontinuidad de la forma, como sucedió en el paso de la proclamación del Reino a la Iglesia de los gentiles"62.

La segunda fase es la de la Eucaristía "en relación con la cena apostólica comunitaria". Dice Ratzinger: "La cena en sentido propiamente dicho va por delante y se concluye antes de la celebración eucarística; las dos acciones eucarísticas (las de Jesús), ahora relacionadas entre sí, se suceden como una única acción, que es puesta entre paréntesis y elevada por la oración de acción de gracias -la Eucharistia-"63. Esta se va así constituyendo en su especificidad "cristiana", aunque tampoco es una mera continuación de la comida cotidiana de Jesús con los suyos. Tiene un carácter de "fiesta" (que se expresa con la ofrenda del vino, un gesto no cotidiano), pero tampoco es una simple repetición de la Última Cena, la cual sería irrepetible si fue una cena de Pascua; la eucaristía se celebra semanalmente, en el día del Señor, aunque incorporando elementos de la tradición pascual. En todo caso, "la novedad cristiana es extrapolada de la Última Cena y unificada, y se celebra después de una cena real de los discípulos" ${ }^{64}$.

Por último, la "forma definitiva" se constituye con la disolución del ágape comunitario. Esta fórmula pronto entró en crisis, tal como quedó atestiguado en el relato de 1 Co 11 . En la misma línea, nuestro autor, apoyándose en otros estudios, sigue describiendo otros aspectos de esta evolución.

Al final de este ensayo incluye una aproximación, claramente menos enfática que todo lo desarrollado hasta aquí, en la perspectiva de mostrar que "si bien se debe rechazar la mera asimilación de la liturgia cristiana a la Última Cena de Jesús, tampoco existe un hiato entre Jesús y la Iglesia" ${ }^{65}$. En todo caso, la acentuación más clara va en la línea de la relativización de la dimensión comensal de la Eucaristía, enfoque que

\footnotetext{
61 J. Ratzinger, La fiesta de la fe..., 54.

62 J. RatZinger, La fiesta de la fe..., 55.

63 J. Ratzinger, La fiesta de la fe..., 56.

64 J. Ratzinger, La fiesta de la fe..., 60.

65 J. Ratzinger, La fiesta de la fe..., 65.
} 
por momentos defiende no sin cierto sarcasmo. Cuando se acentúa el aspecto comunitario-comensal de la celebración eucarístico, a su juicio "la forma y la actitud espiritual de la liturgia pasan a ser en la práctica las propias de una fiesta de vecinos" ${ }^{66}$. El peligro que él ve allí ya lo hemos señalado antes: el de una comunidad cerrada en sí misma, en su dinámica colectiva, en sus propios asuntos, y no vuelta hacia el Padre, en Cristo y en su sacrificio que nos ha merecido y nos merece en cada Eucaristía, como memorial de su Pascua, la redención. Por tal motivo, insiste en ello con pasión:

"La liturgia cristiana -Eucaristía- es por naturaleza la fiesta de la resurrección, mysterium Paschae. Como tal lleva consigo el misterio de la cruz, que es condición previa de la resurrección. Llamar a la Eucaristía la comida de la comunidad es trivializarla [...] La Eucaristía tiene una orientación escatológica y se centra en la teología de la cruz. Esto es lo que quiere decir la Iglesia cuando mantiene el carácter de sacrificio de la misa" ${ }^{67}$.

Con todo esto, quedan planteadas algunas cuestiones importantes para reflexionar, al menos brevemente.

REFLEXIÓN FINAL: LA LITURGIA COMO ACCIÓN DIVINA SALVÍFICA EN Y CON EL SER HUMANO Y SU HISTORIA

Volvamos al comienzo de nuestras reflexiones: ¿Por qué la inquietud por la liturgia y la convicción acerca de su necesaria renovación estuvieron presentes en el inicio mismo del Concilio Vaticano II? ¿Por qué ocuparon un lugar tan destacado entre las señales que las iglesias de todo el mundo enviaron a Roma durante el período de la preparación del evento? Yendo más lejos, podemos preguntarnos: ¿Por qué este tema ocupó un lugar de importancia entre los diversos movimientos de renovación que se desarrollaron en la primera mitad del siglo XX y que confluyeron con fuerza en el Concilio? ¿Qué hay en la experiencia de la liturgia, que la ha puesto tan en el centro del devenir de la Iglesia en todo este tiempo? Rahner y Vorgrimler esbozaron en su momento una triple respuesta, que consideró el contexto histórico, cultural y eclesiológico en que se ubica el Concilio. Para ellos, la preocupación por nuestro tema en el mundo católico reflejaba, en primer lugar, la situación general de la modernidad

66 J. Ratzinger, La fiesta de la fe..., 84.

67 J. Ratzinger, La fiesta de la fe..., 89. 
con su "giro al sujeto" -que no es lo mismo que el "subjetivismo"- y su cuestionamiento radical de la supuesta "objetividad" de signos y ritos meramente externos, con su peligro latente de "mecanicismo, magia y superstición”. En segundo lugar, que el redescubrimiento de la Iglesia como comunidad o pueblo de creyentes, que se había ido tornando una "conciencia intersubjetiva cada vez más clara", lleva a percibir como un verdadero escándalo (Ärgernis), en la celebración litúrgica, un abismo $(K l u f t)$ entre clero y laicos que no tiene ningún fundamento teológico. En tercer lugar, que era explicable que en el Concilio confluyera el impulso y el trabajo adelantado en el movimiento litúrgico, sobre todo con su reconocimiento magisterial a partir de la encíclica Mediator Dei (1947) del papa Pío XII ${ }^{68}$.

Esta triple respuesta me parece, en lo fundamental, muy sugerente. El primer aspecto -la inserción de la inquietud preconciliar y conciliar por la liturgia en el clima cultural de la modernidad-creo que ayuda a entender la crisis experimentada en el posconcilio durante la ejecución de la reforma. Lo que ha acontecido en el ámbito de la liturgia, con la reforma misma y con las críticas de fondo de que ha sido objeto, refleja de modo fiel los vaivenes experimentados por la Iglesia en su relación con el mundo moderno. Ya hemos hecho esta observación en cuanto compete al Papa emérito como representante destacado de la "crítica teológica" a dicha reforma: para él, la crisis de la liturgia es expresión de la crisis de la eclesiología, y sobre todo de la comprensión del sentido de la presencia y de la misión de la Iglesia en el mundo. En sus momentos iniciales, la reforma litúrgica fue expresión de una Iglesia que se reconciliaba con el mundo moderno y que se abría a él con una confianza fundamental, dispuesta incluso a buscar en sus espacios $-y$ no primeramente en los espacios intraeclesiales- la voluntad de Dios manifestada en los "signos de los tiempos"69. Pero para J. Ratzinger, hubo en ello mucho de "optimismo ingenuo", como lo señala en su Informe sobre la fe:

“... podemos y debemos 'abrirnos', pero solo cuando estemos verdaderamente seguros de nuestras propias convicciones [...] Así lo entendían los Papas y los Padres conciliares, algunos de los cuales pudo parecer, tal vez, que se dejaron ganar por aquel optimismo un

68 K. Rahner - H. Vorgrimler, Kleines Konzilskompendium, 37.

69 Cf. esp. la constitución sobre la Iglesia en el mundo actual, Gaudium et spes, 4 y 11. 
poco ingenuo de aquellos tiempos ${ }^{70}$, un optimismo que en la perspectiva actual nos parece poco crítico y realista. Pero si pensaron poder abrirse con confianza a lo que de positivo hay en el mundo moderno, fue precisamente porque estaban seguros de su identidad, de su fe. En contraste con esta actitud, muchos católicos, en estos años, se han abierto sin filtros ni freno al mundo y a su cultura [...] El Vaticano II tenía razón al propiciar una revisión de las relaciones entre Iglesia y mundo [...] Pero demostraría no conocer ni a la Iglesia ni al mundo quien pensase que estas dos realidades pueden encontrarse sin conflicto y llegar a mezclarse sin más"71.

$\mathrm{Su}$ reflexión desemboca, por tanto, en una comprensión más bien “juánica” del mundo, que al parecer le resulta más realista ${ }^{72}$.

A esto habría que agregar la pregunta acerca de lo que se entiende por Iglesia cuando se plantea la pregunta sobre su adecuada relación con el mundo. A ello se refiere, en el fondo, el segundo elemento que Rahner y Vorgrimler identifican entre las principales causas de la especial preocupación del Concilio Vaticano II por la liturgia. No se trataba tan solo de sincerar la percepción de dicha relación (¿una Iglesia contra el mundo moderno, frente a él o inserta en él?), sino además de precisar la identidad del polo eclesial de la misma. Ya lo destacábamos al comienzo: en la liturgia se manifiesta no solo el misterio mismo de nuestra redención en Cristo, sino también e inseparablemente "la naturaleza auténtica de la verdadera Iglesia” (SC 2). Con razón J. Ratzinger/Benedicto XVI ve en el devenir de la liturgia tras el Concilio el reflejo de un asunto más de fondo en el ámbito de la eclesiología, de la autocomprensión de la Iglesia. Por lo mismo, una buena pregunta a la crítica teológica que él representa es en qué medida y de qué modo es posible salvaguardar en esa visión las convicciones fundamentales del Vaticano II sobre el miste-

70 El destacado es mío.

71 J. Ratzinger - V. Messori, Informe sobre la fe, 42.

72 "No son los cristianos los que se oponen al mundo. Es el mundo el que se opone a ellos cuando se proclama la verdad sobre Dios, sobre Cristo y sobre el hombre [...] Superada ya la fase de 'aperturas' indiscriminadas, es hora de que el cristiano descubra de nuevo la conciencia responsable de pertenecer a una minoría y de estar con frecuencia en contradicción con lo que es obvio, lógico y natural para aquello que el Nuevo Testamento llama -y no ciertamente en sentido positivo- 'el espíritu del mundo'. Es tiempo de encontrar de nuevo el coraje del anticonformismo, la capacidad de oponerse, de denunciar muchas de las tendencias de la cultura actual, renunciando a cierta eufórica solidaridad posconciliar" (Ibid., 43). 
rio de la Iglesia (Lumen gentium I) que se despliega históricamente como pueblo de Dios (Lumen gentium II), a cuyo servicio está la diversidad de carismas y ministerios, incluyendo el sacerdocio jerárquico (Lumen gentium III).

¿Cómo puede y debe expresarse de mejor modo este carácter ministerial del oficio del sacerdocio ordenado en la celebración de la liturgia eucarística? ¿Solo en el esquema de rol de "representación” de Cristo ante la Iglesia y de la Iglesia ante Dios, entendido como oficio exclusivo? La pregunta de fondo es, más bien, cuánto y cómo el pueblo de Dios en su conjunto puede legítimamente aspirar a la participación consciente, activa y fructuosa a que invita Sacrosanctum Concilium en su número 11. En los decenios posteriores al Concilio, en la vida litúrgica de las comunidades cristianas reales, vivas, que pueblan el mundo en sus diversas culturas, ha acontecido una auténtica recepción de la reforma litúrgica, que la Iglesia de Roma no puede ignorar. Nadie parece negar que ha habido, sobre todo en los primeros años tras el Concilio, tendencias anárquicas y abusos por exceso o por defecto en la vivencia de la liturgia como expresión de la unidad de la Iglesia universal; pero tampoco se puede negar a priori que el Espíritu Santo ha podido actuar fecundamente a través de las expresiones de fe (lex credendi) que el pueblo sencillo ha descubierto y desarrollado en las nuevas formas de sus celebraciones comunitarias (lex orandi).

Desde esta mirada se pueden entender mejor los acentos de la crítica teológica a la reforma litúrgica, que hemos intentado bosquejar. Dichos acentos van, precisamente, en la línea de rescatar el sentido de "lo sagrado", de la específica búsqueda y glorificación de Dios en la liturgia, en contraposición a aquellos gestos y ritos introducidos por la reforma que parecen reforzar más bien, según esta visión, una eclesiología demasiado autorreferente e inmanentista. En esta línea, por ejemplo, van las reflexiones de nuestro autor sobre el sentido de la celebración "orientada". En segundo lugar, otro gran acento de su crítica es la recuperación de una mayor conciencia y una más elocuente expresión de la liturgia como acción de Dios antes que de la comunidad creyente. De ahí, por ejemplo, su insistencia en la concepción de la liturgia como tiempo y espacio sagrado en que acontece el Misterio; en otras palabras, como lugar (en sentido amplio) de la abertura del cielo o al cielo, para que Dios obre, misterio- 
samente, nuestra redención ${ }^{73}$. Un "lugar" que nos ha legado la Tradición y que, por tanto, no está disponible para cualquier búsqueda innovadora. En definitiva, un lugar privilegiado de apertura al Misterio para descubrir a este como "morada sagrada" y para aprender a habitar en él ${ }^{74}$.

Nos queda la tarea de seguir pensando las consecuencias teológicas y pastorales de una tal concepción de la liturgia, sin apartarse de los grandes principios propuestos por el Concilio Vaticano II y en coherencia, sobre todo, con la Sagrada Escritura. J. Ratzinger ha pensado todo esto desde su matriz agustiniana, con su trasfondo platónico o neoplatónico ${ }^{75}$. En este sentido, debemos decir que es fácil concordar con las convicciones fundamentales del Papa emérito sobre la liturgia, pero es igualmente importante hacerse la pregunta acerca de cuál es la "forma" más adecuada al cristianismo para cumplir esos propósitos. En efecto, es indudable que la comunidad debe volverse, "orientarse" como un todo a Dios en Cristo; pero, ¿dónde y cómo debemos expresar ello, plástica y espacialmente, en la celebración litúrgica? ¿Dónde está Dios, para volvernos todos juntos hacia Él? Del mismo modo, podemos concordar, obviamente, en que la liturgia debe ser un tiempo y un espacio privilegiados para el encuentro de la comunidad con "lo sagrado", con Dios que actúa redentoramente. Pero, ¿̇e qué modo podrá la liturgia expresar de modo adecuado el vínculo entre lo profano y lo sagrado, o entre inmanencia y trascendencia, en el cristianismo como experiencia de la fe en el Dios de la Encarnación?

73 Cf. J. Ratzinger, El espiritu de la liturgia, 59s.

74 Cf. la introducción de O. GonzÁlez de CARDEDAl a la edición española de El espiritu de la liturgia, 27-46, 41s.

75 Cf. J. Ratzinger, Mi vida. Recuerdos, 1927-1977, Madrid 1997, 68, citado por O. GonZÁlez de CARDEDAl, "Introducción”, en J. RatZinger, El espiritu de la liturgia, 35, nota 23; y sobre todo su tesis doctoral: J. Ratzinger, Volk und Haus Gottes in Augustinus Lehre von der Kirche (Karl Zink, München 1954). 
